\title{
A Systemic Functional Approach to Code-switching in Chinese Magazines
}

\author{
X.A. ZHAO \& R.X. Liu \\ Northwestern Polytechnical University, Xi'an, Shaanxi, China
}

\begin{abstract}
With Halliday's functional grammar as the theoretical framework, this paper examines the functions and distributions of code-switching in three different types of magazines from the perspective of experiential, interpersonal, and textual metafunctions. It has found that in experiential function, codeswitching plays the function of filling the vocabulary vacancy, quoting and abiding the cultural constraints; in interpersonal aspect, it plays the function of evaluation and involvement; in textual construction, the function of code-switching is mainly concentrated in lexical cohesion level. This paper tries to provide readers a better understanding of the functions of code-switching.
\end{abstract}

KEYWORD: Code-switching; Metafunction; Magazine

\section{INTRODUCTION}

Code-switching refers to the alternative use of two or more languages in the context of a single conversation. As the connection between Chinese and English increasing, there are more and more English and Chinese code-switching occurring in people's daily communication as well as in newspapers and magazines. As an important media for people to participate and know the social life, magazine can be an effective tool to reflect the undergoing economic, cultural and educational changes in the society. In that case, the articles in magazines are ideal materials to investigate the functions of code-switching.

\section{CODE-SWITCHING AND THREE METAFUNCTIONS IN FUNCTIONAL GRAMMAR}

As a product of languages contact, code-switching has won the logisticians' attention from the 1970s and their approaches mainly lie in four different aspects: sociolinguistic, grammatical approaches, psycholinguistic and pragmatics. From the perspective of sociolinguistics, Appeal, MyserScotton, Cheshire, Gardner-Cholores try to investigate the motivation of code-switching with a micro approach by connecting code-switching with racial factors like age, social status and other social factors $(\mathrm{He} \& \mathrm{Yu}, 2001)$. The research of grammatical approach shows that code-switching is a high systematic language phenomenon, which is a role-dominated behavior (Azuma, 1998). The research in psycholinguistics tries to explore the mind activities of bilinguals when they are conducting the code-switching (Li, 1996). In pragmatics, linguistics mainly utilizes Verschueren's adaptation theory as the framework to analyze codeswitching in different context. According to the adaptation theory, language has three hierarchically related properties: variability, negotiability and adaptability (Verschueren, 1999). Thus the usage of code-switching is closely related with these three properties of language. Though many theories and approaches have been adopted in code-switching research, no approach can fully explain the mechanism and function of code-switching ( $\mathrm{He} \&$ $\mathrm{Yu}, 2001)$. Besides, among the researches on codeswitching, most of the data is collected from oral discourse, few of the data come from the written text. Thus, this paper tries to examine the function of code-switching in magazines by utilizing functional grammar as the theoretical framework.

According to Halliday's functional grammar, language has three metafunctions: ideational function, interpersonal function and textual function (Halliday, 2000). The ideational function refers to the speaker's experience of the real world, the interpersonal function serves to establish and maintain the social relations while the textual function enables the speaker or writer to construct "text" and enable the reader to distinguish a text 
from a random set of sentences. This paper tries to analyze the functions of code-switching in magazines from three different metafunctions.

\section{TYPES AND DISTRIBUTION OF CODE- SWITCHING IN MAGAZINES}

The data of this paper is mainly collected from three different kinds of magazines: Chinese version of Cosmopolitan (Cosmo), China Newsweek and Computer Fan (CFan). Among them, Cosmo is a fashion magazine focusing on finery, hairdressing and metal and carrier development of Chinese women. CFan is targeted for the primary and junior level computer fans, aiming to spread computer knowledge and cultivate computer talents. While the China Newsweek focuses on the influential national and international news, including politic, economic, and cultural news. Each kind of magazine has about 500 pages and code-switching in advertisements or the cover of the magazines are excluded since the functions of code-switching in ads or cover is to arouse readers' attention, according to the relevant research.

Many linguistics have classified code-switching in different types, and among them, Poplack's classification is extensively adopted by many researchers. Poplack identifies code-switching into "intersentential switching", "intrasentential switching" and "extrasentential (tag) switching" (Poplack, 1980). Based on Poplack's classification of code-switching, the author cites the collected corpus of code-switching in these three types of magazines respectively. Their distribution in each magazine is showed in the following table:

Table 1. Distribution of code-switching in different magazines.

\begin{tabular}{|l|l|l|l|}
\hline $\begin{array}{l}\text { Type/Number/Percent/ } \\
\text { Magazine }\end{array}$ & Cosmo & $\begin{array}{l}\text { China } \\
\text { Newsweek }\end{array}$ & CFan \\
\hline $\begin{array}{l}\text { Intersentential } \\
\text { switching" }\end{array}$ & 971 & 355 & 2216 \\
\hline Intrasentential & $92.74 \%$ & $72.75 \%$ & $97.02 \%$ \\
switching & 19 & 5 & 56 \\
\hline Extrasentential & 57 & $1.00 \%$ & $2.45 \%$ \\
switching & $5.44 \%$ & $26.25 \%$ & $0.53 \%$ \\
\hline Total & 1047 & 488 & 2284 \\
& $100 \%$ & $100 \%$ & $100 \%$ \\
\hline
\end{tabular}

From this table, we can see, most of the codeswitching in these magazines are intrasentential switching however the percentages of each kind of switching are various in different magazines. Cfan appears more code-switching than the other two magazines because that most of the proper nouns of computer technology originate from English. There is more tag switching in China Newsweek since many proper nouns for organizations and countries in news reports need explanation. Based on the analysis, the author finds that most of the intersentential switching in China Newsweek and Cfan is noun switching while there is a comparatively large percentage of adjective and verb switching in Cosmo. The figures are illustrated in Table 2.

Table 2. Distribution of code-switching in different magazines.

\begin{tabular}{|c|c|c|c|c|}
\hline Word & $\begin{array}{c}\text { Noun } \\
\text { phrase }\end{array}$ & $\begin{array}{c}\text { Adj. } \\
\text { phrase }\end{array}$ & $\begin{array}{c}\text { Verb } \\
\text { phrase }\end{array}$ & others \\
\hline Number & 881 & 28 & 24 & 38 \\
\hline Percent & $90.7 \%$ & $2.88 \%$ & $2.47 \%$ & $3.91 \%$ \\
\hline
\end{tabular}

\section{ANALYSIS OF METAFUNCTIONS OF CODE- SWITCHING IN MAGAZINES}

From the above data, the author finds that both the number of code-switching and the type of codeswitching differ in different magazines. In order to explore the causes of this and also to find out the functions of code-switching, this paper will adopt functional grammar as the theoretical framework to discuss the ideational, interpersonal and textual function of code-switching.

\subsection{Ideational function}

From the perspective of ideational function, the occurrence of code-switching is to better express the experience of the author's world.

\subsubsection{Lexical gap filling}

A lexical gap is an absence of a word in a particular language. In Cfan, there are many jargons which are directly introduced from English and there is no Chinese translation for them, thus the codeswitching occurs to fill the lexical gap. For example:

(1)Windows 8 nei zhi SkyDrive wang pan (CFan/201322/P36)

(The SkyDrive is internally installed in Windows 8 system.)

(2)Jie zhe dian ji ping mu shang de ren yi wei zhi, ci shi Refocus hui zai hou tai zi dong kai shi gong zuo. (CFan/201324/P60)

(Click any part of the screen, the Refocus can work automatically in the background.)

In these examples, the Chinese meaning of "SkyDrive" is "network hard disk", which is not coordinated with the English meaning of SkyDrive. And the Chinese meaning of "refocus" is "to adjust the focus", which is different from its English meaning: "a function of telephone to take photos". Thus the author of these articles switching them into English as the reference. Besides that, many brands in fashion magazines also have no Chinese 
translation (like Calvin Klein) and the editor of these magazines will only use the English name.

\subsubsection{Abiding the cultural convention}

People can use language to express their idea and experience of real world, while the usage of language is influenced by many social factors. In order to make successful communication, many conventions should be abided.

(3)Ni xu yao de App, sui shi sui di tao zhu ta de iCondom. (Cosmo/201323/284)

(You need an app to control his icondom whenever and wherever you want.)

In Chinese culture, topics on sex are not openly discussed and the editors should use the English version of these words to express their meaning.

\subsubsection{Quotation}

In functional grammar, quotation is called projection, meaning something that has been articulated before is now projected into another text (Wang, 2013). Using quotation is an effective way to describe the feeling or intention of the speaker. For example:

(4) Yin wei wo dui zhe ju hua hen you gong ming: "The more people I know, the more I like dogs."(COSMO/201321/P107)

(These words resonate with me a lot: "The more people I know, the more I like dogs.")

This example comes from the interview of Jaycee Fong, son of Jackie Chan. Growing up in America, he uses the English proverb rather than the Chinese one to show his attitude toward life which is more vivid and more suitable for him.

(5) Ruan jian jie mian shang de "PC name" tian xie nei wang IP di zhi, "User name" he "Password" jiu shi ji suan ji ming he deng lu mi ma. (CFan/201323/P25)

(In the software interface, you should write down your LAN IP address in the option called "PC name", and write down the user's name and your password in the options of "User name" and "Password" respectively.)

Example 5 shows how to realize the remote control for the user's computer. In the description of working procedures, several English terms for IT will appear in the software interface. In order to describe the procedures clearly, the editor should directly quote these word and explain them to the new hand users.

\subsection{Interpersonal function}

Language is a very useful media for people to establish, negotiate and maintain interpersonal relations. In Wang's research of code-switching in newspapers, she regarded code-switching as evaluation and involvement resources (Wang, 2013).
There is no difference for code-switching in magazines.

\subsubsection{Code-switching for evaluation}

The evaluation function of language refers to the function of expressing one's attitude, emotion and judgment by language. In fashion magazines, much code-switching is adopted by editors to show the fashion and internationalism of their articles.

(6) Yue open, yue mei li. (COSMO/201323/P158) be.)

(The opener she is, the more charming she will

In this example, "open" is used as a way to show the English awareness of the editor thus to show his/her article is quite fashionable. Apart from that, code-switching can also be used to express authors' attitude politely.

(7)Du xing shi bug, shi cheng $x u$ shang de cuo wu. (COSMO/201321/P102)

(The desire of gambling is a bug, a mistake in the software.)

This sentence comes from an interview. As a derogatory term, the Chinese version of "bug" is avoided by the speaker to show his attitude politely and to make a smooth conversation.

\subsubsection{Code-switching for involvement}

Involvement is concerned with how specialized the discourse is in terms of its reader and what interpersonal world are shared by interactants. The society can be divided into different categories thus there are different language communities (Wang, 2013). The social categories can be distinguished by the language that people use. In IT and fashion magazines, the overloaded code-switching can indicate the readership: only the one who can understand this switching can be the potential readers. For example:

(8)NVIDIA Inspector ke yi dui xian ka qu dong jin xing feng $f u$ de zi ding yi xiu gai. (CFan/201324/P54)

(NVIDIA Inspector can modify the video driver with rich customization.)

In this example, only the IT fan can understand that NVIDIA is a brand-name for chip. Thus for this article, only the computer fans are involved as readers. However, for the China Newsweek, in order to enlarge its readership, the articles in it should be as easily understood as possible.

(9) Zhe shi zhong guo di yi tiao cai yong SCADA (jian kong yu shu ju cai ji) xi tong quan zi dong kong zhi de guan dao. (China Newsweek/201344/P61)

(This is the first oil pipeline in China that can realize the full automatic control with SCADA system.)

In China Newsweek, most code-switching is tag switching and the editors will use it as further explanation for readers to understand jargons in any register. Besides, they may also use some colloquial 
way of code-switching to shorten the distance with the reader.

\subsection{Textual function}

The textual function concerns about the organization of the whole text and can make the ideational function and interpersonal function into a whole texture. In these magazine articles, most of the codeswitching concentrates on the lexical-level, thus its textual function is mainly illustrated through lexical cohesion. Based on Halliday's functional grammar, lexical cohesion includes reiteration and collocation. While among reiteration there are four types: repetition (same word); synonym; superordinate and general word. The referential relation of these four types is respectively: same referent; inclusive; exclusive and unrelated (Halliday, 2001). Among all the data collected in the magazines, only the switching of repetition and synonym is found.

(10)Ha, shi shang de Dress code shuo xuan mei na me xuan. Dan shi shi shang de Dress code shuo xuan ye ting xuan......Tian tian fa bu shi shang de Dress code, er qie hai yu shi ju jin. (COSMO/201323/P30)

(Ha! The dress code of fashion is not as mysterious as you think..... But the dress code of fashion is really very mysterious....they will release all kinds of information on dress code every day and try to keep pace with the times. )

(11)Zhen zheng de gu dong jiao zuo Antique, jin dai de "gu dong" bei jiao zuo Vintage......Xi fang ren cheng ta wei "Old". (COSMO/201323/P135)

(The real antique is called "Antique"; in modern times, "Antique" is named as "Vintage"..... the western usually call it "Old".)

In Example 12, "dress code" has appeared three times and the last two "dress code" can be regarded as the anaphoric relation to the first one, which contributes to the cohesion of the whole text. What's more, the repetition of "dress code" helps to highlight the topic of the article and make the readers easily get what the editors want to express. While in Example 13, "antique", "vintage" and "old" are synonyms which all mean something that is made in an earlier time with good quality or great value. The code-switching of these three words can make the whole paragraph more coherent. In China Newsweek, especially in the international news, there are many code-switching of acronyms for organizations or international committees, such as
Group 8, UNDP. Once the acronyms are introduced, it will appear in the rest part of the text.

Apart from these lexical cohesions, there are also some other code-switching like "ok", "by the way", "so" in the data. The function of these discourse markers is to organize the text and make a connecting link between the preceding and the following text.

\section{CONCLUSION}

From the analysis of code-switching, it's obvious to know that the types and distributions of codeswitching differ in different kinds of magazines. Then, taking Halliday's functional grammar as the theoretical framework, the author analyzes the function of code-switching in these magazines. It's found that code-switching in some way can realize the metafuntions of language: the ideational function, the interpersonal function as well as the textual function. The findings help readers to understand code-switching, especially the codeswitching in written text in a new and systematic perspective, and this study also suggest a new the research field for functional grammar.

\section{REFERENCES}

[1] Azuma, S. 1998. Meaning and form in codeswitching. In Rodolfo Jacobson (eds), Codeswitching worldwide. Berlin, New York: Mouton de Gruyter.

[2] Halliday, M.A.K. 2000. An introduction to functional grammar. Beijing: Foreign Language Teaching and Research Press.

[3] Halliday, M.A.K. 2001. Cohesion in English. Beijing: Foreign Language Teaching and Research Press.

[4] He, Z.R. \& Yu, G.D. 2001.Researches on codeswitching. Xiandai waiyu ("Modern foreign languages") 91(1): 8595.

[5] Li, D.C.S. 1996. Issues in bilingualism and biculturalism: a Hong Kong case study. New York; Washington, D.C/Baltimore; Bern; Frankfurt am Main; Berlin; Vienna; Paris: Peter Lang Publishing Inc.

[6] Poplack, S. 1980. Sometimes I start a sentence in Spanish $\mathrm{y}$ ternimo en español: towards a typology of codeswtiching. Linguistics 18:581-618.

[7] Wang, J. 2013. Code-switching as social practice: a systemic functional approach to the Chinese/ English code-switching in Chinese newspapers. Guangzhou: Sun Yat-sen University Press.

[8] Verschueren, J. 1999. Understanding pragmatics. London, New York, Sydney, and Auckland: Arnold. 